\title{
The influence of African Herbal Formula on the haematological parameters of trypanosome infected rats
}

\author{
Okochi $\mathrm{VI}^{1}$, Okpuzor $\mathrm{J}^{2 *}$, Okubena $\mathrm{MO}^{3}$, Awoyemi $\mathrm{AK}^{4}$ \\ ${ }^{1}$ Department of Biochemistry, University of Lagos, Akoka, Yaba, Lagos, Nigeria. \\ ${ }^{2}$ Department Of Cell Biology and Genetics, University of Lagos, Akoka, Yaba, Lagos, Nigeria. \\ ${ }^{3}$ Bena Farms Limited, ljebu-Ode, Ogun State, Nigeria. \\ ${ }^{4}$ Samaritan Spiritual Healing Home, Ibadan, Oyo State, Nigeria.
}

Accepted 22 August 2003

\begin{abstract}
A herbal mixture of herbs code named African Herbal Formula (AFH) influenced the state of anaemia in trypanosome infected rats. Observations showed that the formula has an effect on the haemopoietic system manifested by a positive increase in the levels of haemoglobin, packed cell volume and red blood cell while the white blood cell and lymphocyte levels were decreased. AHF also delayed the proliferation of the parasites and improved the level of the characteristic weight loss associated with trypanosomiasis.
\end{abstract}

Key words: African Herbal Formula, trypanosomiasis, anaemia.

\section{INTRODUCTION}

For several decades trypanosomiasis has continued to contribute adversely to the economic and social well being of sub-Saharan Africans. This scourge remains a pressing challenge especially to African medical scientists for possible action plan that would be basic on the poor resources of these communities. The articulation of such plan would include both preventive measures and treatment modalities.

Towards this stated goal, we started by studying purine metabolism in Trypanosoma vivax (Okochi et al., 1983; Okochi et al., 1995; Okochi, 1986). However, there is a need for an inward approach towards solving our diverse health problems. This has motivated a search for local herbs that can possibly have trypanocidal activity.

The mixture code-named African Herbal Formula (AHF)

${ }^{*}$ Corresponding Author: E-mail:joyokpuzor@yahoo.com. consists of a combination of plant materials originally developed by a family in southern part of Nigeria and passed on to generations. Over the years, AHF has been applied by members of the family and close-associates for all kinds of health problems and it is very popular among the low socio-economic class. Medical research scientists, including physicians at tertiary health centers in Nigeria have consistently rebuffed the use of this formula based on the genuine premise that there has been no previous scientific study of AHF on human and/or experimental animals. But oral interviews with random end-users usually concluded a beneficial effect on their physical well being. These end users include both low and middle socio-economic class families. The claim of possible therapeutic action of AHF, either along or in combination with other local herbs for the treatment of myriad of pathological conditions, has aroused our curiosity. We were, therefore, motivated to critically evaluate the possible effect of AHF on blood components following a parasitological challenge. 
This study was designed to evaluate to what extent this herbal formula can influence the state of anemia in trypanosome infected rats since it is a well known characteristic feature of trypanosomiasis.

\section{MATERIALS AND METHODS}

\section{Collection and Preparation of AHF}

AHF was donated to us by a member of the originating family as a rusty brown powder with a lot of cellulose fibers. It is an unknown mixture of herbs. The components of the formula, as analysed by a consultancy group of the school of Pharmacy, University of Lagos, shows that the product contains carbohydrates, proteins, tannins, saponins, coumarins and iron. Alkaloid was not detected in the mixture. The working solution was prepared by dissolving $15 \mathrm{~g}$ of the product in $100 \mathrm{ml}$ of distilled water. The mixture stirred for about five minutes and filtered to remove cellulose fibers. The resulting solution was kept in the refrigerator at $4^{\circ} \mathrm{C}$ and $1 \mathrm{ml}$ was given daily to each of the designated rats.

\section{The parasites}

The Trypanosome brucei used for this study was obtained from the Nigerian institute for Trypanosomiasis Research, Vom, Jos, Nigeria. Each of the recipient animals was inoculated with $3.6 \times 10^{3}$ T. brucei cells.

\section{Experimental animals}

Adult male and female rats were obtained from the animal house of the College of Medicine of the University of Lagos, Nigeria and were allowed to acclimatize for a week in the animal unit of the Department of Biochemistry before the study. All rats were fed with commercial pellets (Pfizer Nigeria Plc., Ikeja, Nigeria) and watered ad libitum throughout the duration of the study.

\section{Weight assessment}

As an index of the physical status of the animals, the weight of each animal was monitored daily over the period of study.

\section{Design of the study groups}

Group I: Uninfected and untreated (control).

Group II: Uninfected and treated with AHF. Group III:Infected and untreated.

Group IV:Infected and treated with AHF.

\section{Determination of degree of parasitaemia: Film preparation}

A drop of blood was taken from the tail vein of the infected rats and placed at a distance of about an inch from one end of the microscopic slide and dispersed along the length of the slide with one another. The film formed was air-dried and then fixed with Leishmann stain. After rinsing with distilled water and leaving it to air-dry, the slide was put under oil immersion and number of parasites per 1000 red blood cells were counted.

\section{Bleeding and analysis of the haematological parameters}

At the end of the experiments (14 days), each animal was anaesthesized with chloroform and sacrificed by cutting through the jugular vein. The blood pooled from all the animals in each group was collected into bottles containing EDTA as anticoagulant.

The red blood cells (RBC), white blood cells (WBC) and the differentials were estimated using the improved Neubauer counting chamber as described by (Dacie and Lewis, 1991). The Hemoglobin $(\mathrm{Hb})$ concentration was determined by the Cyanmethhemoglobin method and the packed cell volume (PCV) was determined by the micro method, also as described by Dacie and Lewis (1991).

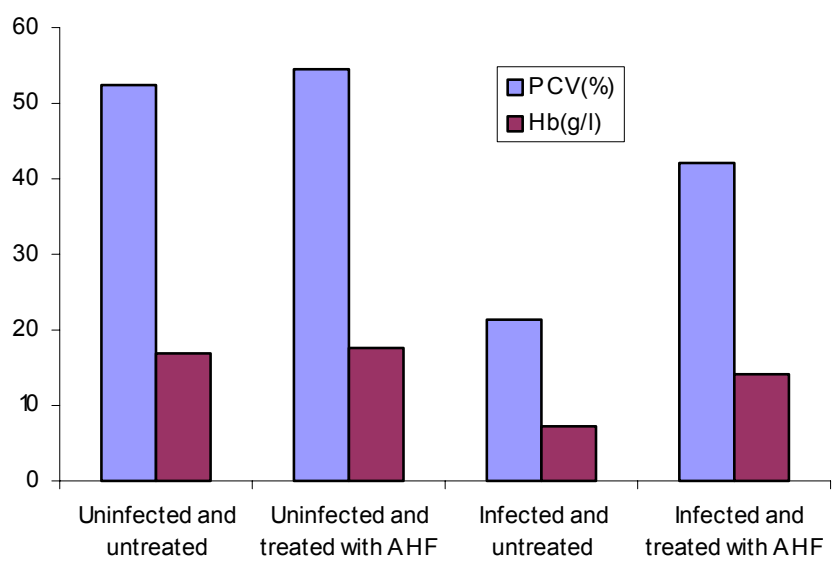

Figure 1. Changes in packed cell volume (PCV) and haemoglobin (HB) of rats treated and untreated with AHF.

\section{RESULTS}

The results suggest that the administration of AHF positively improved the blood components of trypanosome infected rats. This observation is reflected by the increased red blood cell count (RBC), raised haemoglobin $(\mathrm{Hb})$, packed cell volume $(\mathrm{PCV})$, decreased white blood cells (WBC) and lymphocytes in the infected and treated rats, all of which are represented in the bar charts shown in Figures 1 to 4 . Figure 1 shows the level of haemoglobin and PCV of trypanosome infected rats. The lowest level of $\mathrm{Hb}(7.2 \mathrm{~g} / \mathrm{L})$ was observed in the infected and untreated rats (group III), followed by 14.0 $\mathrm{g} / \mathrm{L}$ for the rats that were infected and treated with AHF (group IV). The control rats (group I) that were uninfected and untreated had an $\mathrm{Hb}$ level of $17.0 \mathrm{~g} / \mathrm{L}$, while those in group II that were uninfected and treated with AHF recorded an $\mathrm{Hb}$ level of $17.5 \mathrm{~g} / \mathrm{L}$. In Figure 1 also, the percentage PCV follows the same pattern as for the haemoglobin with rats infected and untreated having the lowest value of $21.5 \%$. The value obtained for the RBC (Figure 2) also agrees with the reported trend for PCV and Haemoglobin above. The lowest value was observed for the infected and untreated group $\left(2.45 \times 10^{6}\right.$ cells $)$ 
followed by a level of $3.0 \times 10^{6}$ for the infected and treated rats, then $3.1 \times 10^{6}$ cell for the control animals and finally, $3.8 \times 10^{6}$ cells for the uninfected and treated with AHF. As would be expected (Figure 3 ), the animals in group III that were infected and untreated recorded great increase in the total WBC level $\left(10,600 \mathrm{~mm}^{3}\right)$ in contrast to the control rats (group I) that had WBC values of $2,800 \mathrm{~mm}^{3}$. The WBC for the rats that were infected and treated with AHF (group IV) was $3,600 \mathrm{~mm}^{3}$ while that of the uninfected and treated rats (group II) was $3,200 \mathrm{~mm}^{3}$.

The white cell differential counts (Figure 4) showed a decrease for the neutrophils in group III (16\%) and group II $(22 \%)$ rats, as against $40 \%$ recorded for the control rats and $60 \%$ for the rats in group IV. The lymphocytes increased in the reverse order to the white cell differentials. It was $84 \%$ for the infected and untreated (group III), $76 \%$ for the uninfected and treated (group II), $60 \%$ for the uninfected and untreated (control) and $40 \%$ for the infected and treated (group IV).

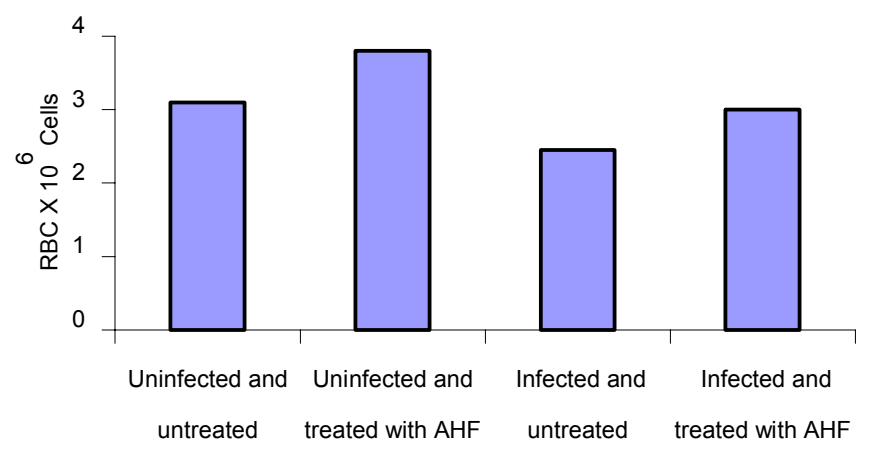

Figure 2. Changes in red blood cell count (RBC) of rats treated and untreated with AHF.

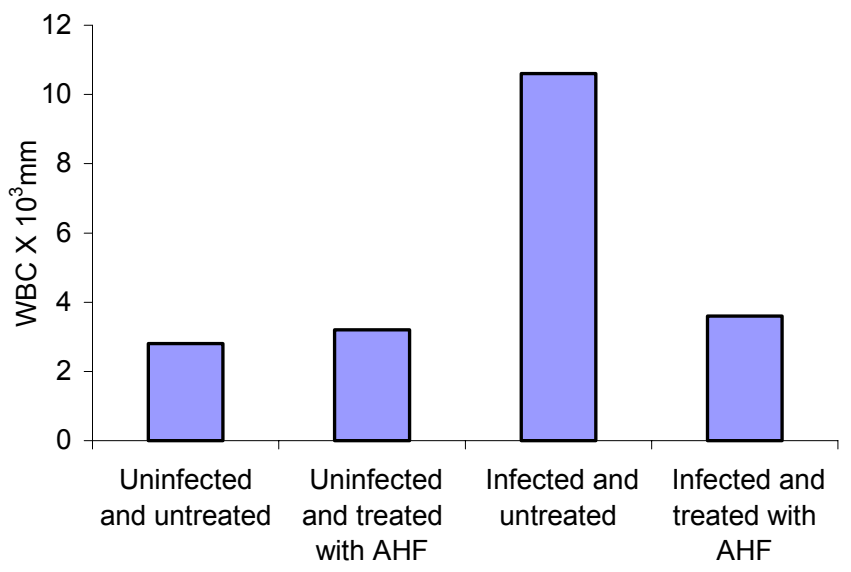

Figure 3. Changes in white blood cells (WBC) of rats treated and untreated with AHF.

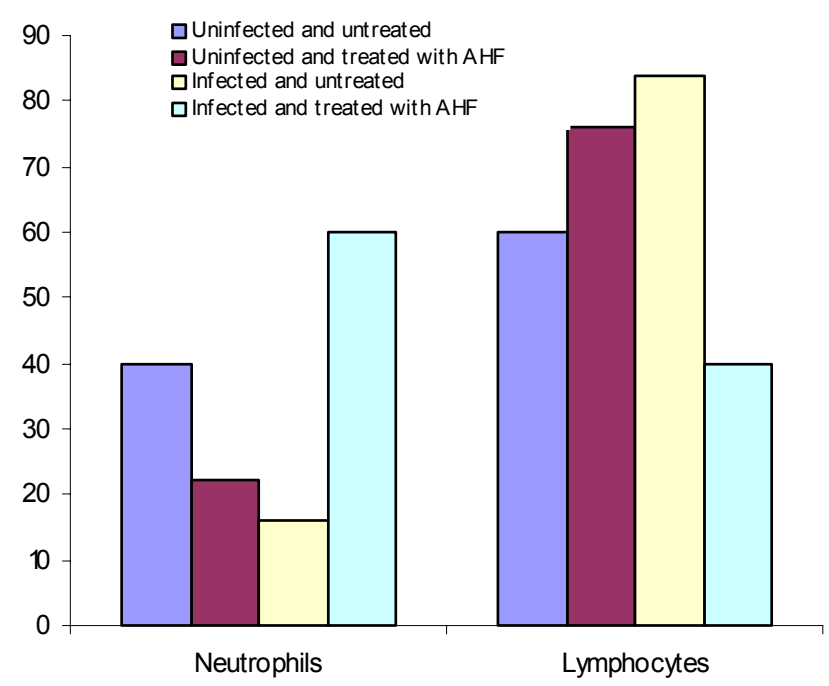

Figure 4. Changes in differentials of rats treated and untreated with AHF.

Figure 5 illustrates the pattern of weight changes among the animals in groups I to IV. Six animals making up the control group were neither infected with $T$. brucei nor treated with AHF and their average weight at the beginning of the study was $120 \mathrm{~g}$, which came to $175 \mathrm{~g}$ at the end of 14 days indicating a weight gain of $31.43 \%$. The animals in group II which were also uninfected and treated with AHF daily had weight changes varying from an average of $133 \mathrm{~g}$ to $186 \mathrm{~g}$ (for the six rats in the group) indicating a $28.5 \%$ in weight gain for members of the group. Over the study period, the animals in group III that were infected and untreated with AHF had a steady weight decline from $157 \mathrm{~g}$ at the beginning of the experiment to $120 \mathrm{~g}$ at the end, a $23.57 \%$ weight loss. Similarly, the weight of the rats in group IV that were infected and treated with AHF lost weight (from $150 \mathrm{~g}$ to $127 \mathrm{~g}$ ), a percentage weight loss of 15 percent.

Table 1 showed that the degree of parasitaemia in group $B$ was high resulting in the death of all the rats after fourteen days while in group $A$, the elevated degree of parasitaemia was not enough to kill the rats at the end of fourteen days. Moreover, the prepatent period was six days for rats in group $A$ and three days for group $B$.

\section{DISCUSSION}

In Nigeria, several research scientists have focused their activities in the last two decades or so on trying to identify and standardised active ingredients in herbal preparations used by the people that believe so much on traditional medicine due to their cultural background. This development has brought to limelight the efficacy of African traditional medicine. A lot of scientific investigations have followed this development. Muyibi et 


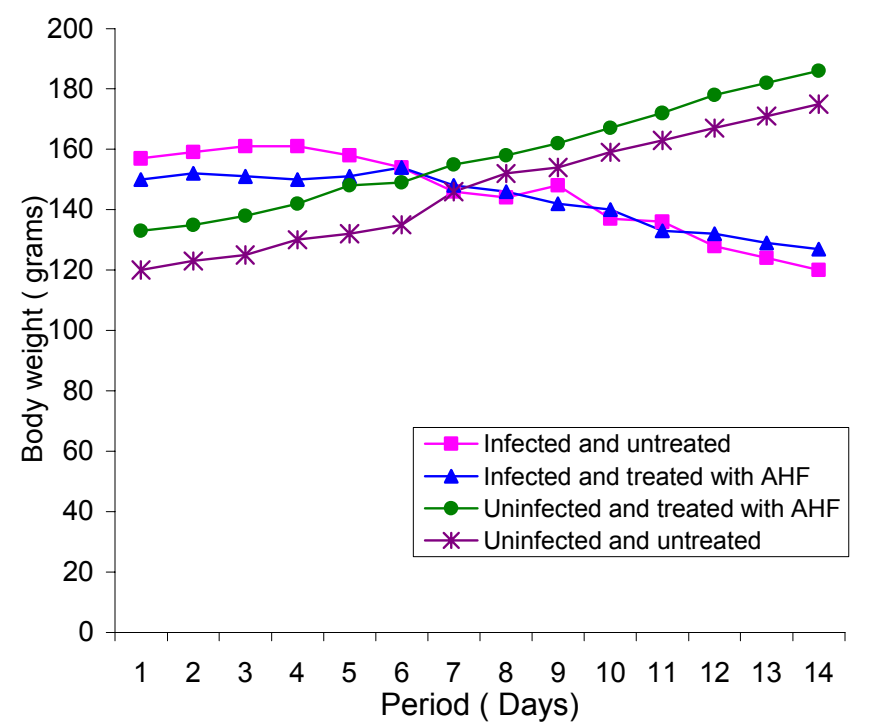

Figure 5. Weight changes in experimental rats treated and untreated with AHF.

Table 1. Average parasitaemia (\%) in study rats.

\begin{tabular}{|c|c|c|}
\hline Days & Group A & Group B \\
\hline 1 & 0 & 0 \\
2 & 0 & 0 \\
3 & 0 & 0 \\
4 & 0 & 0.65 \\
5 & 0 & 1.8 \\
6 & 0 & 3.15 \\
7 & 0.15 & 5.6 \\
8 & 0.50 & 10.15 \\
9 & 1.40 & 16.90 \\
10 & 3.20 & 24.65 \\
11 & 5.50 & 31.30 \\
12 & 13.10 & 42.0 \\
13 & 39.75 & 50.70 \\
14 & 47.40 & All died \\
\hline
\end{tabular}

Group A: Infected and treated with AHF. Group B: Infected and untreated.

al. (2000) showed that the leaf extract of Cassia occidentalis produced significant decreases in packed cell volume, haemoglobin concentration and red blood cells but did not influence the white blood cells. Adisa et al. (1999) working with albino rats infected with T. brucei observed in their haematolobiological studies an increase in the WBC and a corresponding decrease in PCV values.
The observed effect of the AHF from our studies on the blood components of trypanosome-infected rats is attributed to its effect on the haemopoietic system. This argument is supported by the increased red cell mass, haemoglobin and a corresponding rise in the white cell count, following the administration of AHF to the uninfected animals. Furthermore, there was a rise in the percentage lymphocyte level in the uninfected animals, which were treated with AHF. This may implicate immunological pathways. Nevertheless, our observation on the parasite load of the experimental animals is in agreement with our suggestion. The parasite load in the blood stream of the infected and treated rats, when compared with the untreated group, suggests that AHF may positively influence the defence capacity of the treated animals, particularly at the early stages of the infection. Firstly, the prepatent period in the treated animals was longer than in the untreated group (being six days for the former and three days for the latter). Secondly the proliferation of the parasites was appreciably slower in the treated rats than in the untreated ones. The delayed proliferation persisted for about 12 days post-infection, which may imply that it was more difficult for the parasites to establish their infectivity in the presence of AHF than in its absence. Since the infected and untreated animals did not exhibit the same response as the treated, it is reasonable to suggest that AHF must have influenced the defence mechanism of the host rats. After 12 days, there was a sudden upsurge in parasitaemia in the treated group despite continuous treatment which suggests a breakdown of the host's defence system. Possibly, the parasites must have acquired resistance to the herbal formula since it is known that trypanosomes possess variant surface antigens (VSA) which enable them evade their hosts immune response (Vickerman, 1974). However, more work is in progress to establish if the upsurge is due to resistance to the AHF by the trypanosomes.

The positive effect of AHF can further be deduced from the weight status of the experimental animals. Even though the treated and untreated rats (in the infected groups) lost weight as a result of parasitic infection, the weight of the treated rats remained consistently higher than those of the untreated animals indicating that the treated group was in a better physical state to eat more than the untreated ones. They were, therefore, more able to contain certain weight loss due to trypanosomiasis (Urbina, 1993).

Therefore, this study has provided evidence that AHF has a potential for influencing the state of anaemia in trypanosome infected rats. Even if it cannot destroy the trypanosomes, it can at least boost the capacity of the host to fight the invading parasites. This makes further work on this formula (alone or in combination with order herbal preparations) worthwhile because parasitic diseases accompanied by severe anaemia are prevalent in the African continent. The social implication of 
exploring the medical potential of AHF will be easy availability and cheap cost. This will go a long way in alleviating the usual problems of health-care delivery, particularly, in relation to financial resources, logistics of distribution, and at the same time, atone the cultural yearnings of the people.

\section{REFERENCES}

Adisa OA, Ajayi, OA, Awujo NC, Thomas, BN (1999). Haematolobiochemical changes in albino rats infected with Trypanosoma brucei brucei. Nig. Quart. J. Hosp. Med. 9:238-240.

Dacie JV, Lewis SM (1991). Practical haematology $7^{\text {th }}$ (ed.) ELBS with Churchill Living stone, England pp. 37-85.

Losos GJ, Ikede BO (1973). Review of pathology of diseases in domestic and laboratory animals caused by Trypanosoma congolense, $T$. vivax, $T$. brucei brucei, $T$. rhodesiense and $T$. gambiense. Vet. Path. (Suppl. 9) 1-71.

Murray M (1979). Anaemia of bovine African trypanosomiasis: an overview. Losos GJ, Chovinard A. (eds). In pathology of trypanosomiasis: Intern. Dev. Res. Cent. Ottawa Canada Pub. No. 1320.

Muyibi SA, Olorode BR, Onyeyili PA, Osunkwo UA, Mohammad BY, Ajagbonna OP (2000). Haematological and histopathological changes of Cassia occidentalis leaf extract in rats. Nig. J. Nat. Prod. Med. 4: 48-52.

Okochi VI (1986). Transport and metabolism of adenosine in T. vivax. $\mathrm{PhD}$. Thesis University of Lagos, Lagos, Nigeria.

Okochi VI, Abaelu AM, Akinrimisi EO (1983). Studies on the mechanism of adenosine transport in Trypanosoma vivax. Biochem. Int. 6:12939.

Okochi VI, Abaelu AM, Omoyele O, Akinrimisi EO (1995). Effect of formycin $A$ and protein inhibitors on adenosine transport in Trypanosoma vivax Biokemistri. 5: 35-40.

Okochi VI, Kazeem AA,Gbenle GO, Fagbenro-Beyoku AF, Dare A Arukwu U (2001). Effect of Allium sativum (Garlic) water extract on Trypanosoma brucei infection in laboratory rat. Biokemistri 11: 9-15.

Urbina JA, Marchan E, Lazardi K, Visbal G, Apitz-Castro R, Gil F, Aguire T, Piras MM, Piras R (1993). Inhibition of phosphotidylcholine biosynthesis and cell proliferation in Trypanosoma cruzi by ajoene, an antiplatelate compound isolated from garlic. Biochem. Pharmacol. 45: 2381-2387.

Vickerman K (1974). Antigenic variation in African trypanosomes. In: Porter R, Knight J. (eds) Parasites in the immunized host. Mechanisms of survival Liba foundation symposieum 25 (New series). Associated Scientific Publishers. Amsterdam, The Netherlands, pp. 53-80.

Vickerman K (1979). Antigenic variation in trypanosomes. Nature 273: 613-617. 